\title{
A MARCA DE ORIGEM: COMPARANDO COLLEGES NORTE- AMERICANOS E FACULDADES BRASILEIRAS
}

\author{
ARABELA CAMPOS OLIVEN \\ Programa de Pós-Graduação em Educação e Programa de Pós-Graduação \\ em Sociologia/Universidade Federal do Rio Grande do Sul \\ aoliven@uol.com.br
}

\begin{abstract}
RESUMO
Colleges nos Estados Unidos e faculdades no Brasil existiam antes da criação de universidades. Instituições radicalmente diferentes, têm marcado profundamente o desenvolvimento da educação superior nos dois países. O college nasceu privado, mais ligado ao seu Board of Trustees (Conselho de Curadores) do que à Coroa Inglesa, e com profunda orientação religiosa. As primeiras faculdades no Brasil, criadas por Dom João VI, seguiam o modelo das Grandes Escolas Francesas: eram instituições seculares, de formação de profissionais. Seus professores costumavam ser médicos de renome que se dedicavam tangencialmente às atividades docentes. Nos Estados Unidos, os professores moravam nos colleges com os estudantes e assumiam a responsabilidade na formação do caráter de seus alunos, estando no lugar dos pais (in loco parentis). Este trabalho traça um paralelo entre a educação superior nos Estados Unidos e no Brasil, dando ênfase à influência do modelo de origem no desenvolvimento dos dois sistemas. Procura mostrar como o exemplo das instituições fundantes se constitui em marca indelével, presente nos períodos tanto de continuidade como nos de mudança dos sistemas.
\end{abstract}

ENSINO SUPERIOR - HISTÓRIA DA EDUCAÇÃO - BRASIL - ESTADOS UNIDOS

\begin{abstract}
THEMARK OFORIGIN: A COMPARISON BETWEEN COLLEGES IN THE UNITED STATES AND FACULDADES IN BRAZIL. Colleges in the United States and faculdades in Brazil were the first higher education institutions in those countries which existed before universities. These two old and traditional institutions, radically different from each other, have marked deeply the development of higher education in both countries. Most colleges were private from the
\end{abstract}

Esse artigo é parte do projeto de pesquisa "Universidade: continuidade e ruptura" e contou com a colaboração de Aline Durrán S. de Bittencourt, bolsista de iniciação científica do Conselho Nacional de Desenvolvimento Científico e Tecnológico - CNPq. 
beginning, they used to be more dependent on their Board of Trustees than on the English Crown, having also a profound religious orientation. The first faculdades in Brazil were founded by Dom João VI, Prince Regent, in the beginning of the XIX century, almost two hundred years latter than Harvard. They followed the French Great Schools model: were lay institutions, with a strong professional orientation. Their professors used to be well known medical doctors, usually not strongly committed to their academic activities. In the United States, professors lived in the college with the students and they assumed the responsibility of building their character, through their life examples and their in loco parentis function. This article draws a parallel on higher education in the United States and Brazil, placing greater emphasis on the influence of the origin of the two systems. It shows how the model of the first institutions in each country turned out to be a significant mark which can be felt until our days.

HIGHER EDUCATION - HISTORY OF EDUCATION - BRAZIL - USA

In loco parentis, alma mater, greek system, fraternity, board of trustees, commencement... são termos bastante usuais nas universidades americanas mas pouco familiares a nós brasileiros, mesmo àqueles que fizeram sua formação pósgraduada nos Estados Unidos. Eles não têm tradução para a nossa realidade, como são intraduzíveis para o inglês palavras como cátedra vitalícia, cursinho, vestibular, excedentes, gabaritar, trote etc. Esses termos tão diferentes refletem realidades socioeducacionais distintas, que têm raízes profundas, algumas remontando às origens de cada um dos sistemas de educação superior nos dois países.

Este artigo tem como finalidade analisar essas diferenças, dando ênfase à influência da origem no desenvolvimento de cada um dos dois sistemas. Procurarei mostrar como o modelo das instituições fundantes se constitui em marca indelével, presente nos períodos tanto de continuidade como nos de ruptura dos sistemas, quando são realizadas mudanças significativas em instituições, através de políticas internas e/ou de reformas legais. Como a influência norteamericana no Brasil aumentou a partir da Reforma Universitária de 1968 e do desenvolvimento do sistema de pós-graduação que lhe seguiu, farei referência especial à relação entre graduação e pós-graduação nos dois países.

\section{A EDUCAÇÃO SUPERIOR NOS ESTADOS UNIDOS}

\section{A instituição fundante: o college norte-americano}

A primeira instituição de ensino superior nas colônias inglesas da América foi Harvard; college fundado em 1636 por um grupo de orientação calvinista, 
logo após sua chegada ao Novo Mundo. Durante o período colonial foram fundados mais sete colleges de diferentes denominações. Desse grupo, sete permanecem privados até hoje. Na Inglaterra, inspiração para as colônias britânicas do Novo Mundo, o sistema de ensino superior dispunha de um grande número de colleges ligados a uma das duas universidades tradicionais - Oxford e Cambridge -, únicas instituições que conferiam graus acadêmicos. Esse era um modelo muito complexo para ser adotado nas colônias, considerando-se as limitações impostas pelas suas realidades socioeconômicas.

Apesar de copiarem, na medida de suas possibilidades, vários aspectos da tradição universitária inglesa, havia uma grande independência dos colleges coloniais em relação à metrópole. Muitos ingleses que deixaram a Inglaterra nessa época fizeram-no para escapar de perseguições religiosas. Assim, a maior parte da população de cada nova colônia se constituía, predominantemente, de uma diferente denominação do protestantismo e os fundadores dos colleges coloniais, em grande parte não conformistas, temiam a interferência da Inglaterra na orientação religiosa do ensino superior.

Os colleges formavam, principalmente, pastores e líderes religiosos para as novas comunidades. A fim de alcançar tal objetivo, a formação do caráter era essencial e isso só era possível pela leitura e discussão da Bíblia, do estudo dos clássicos e de uma rígida disciplina que incluía assistência regular aos serviços religiosos e contato próximo entre alunos e professores, constituindo estes últimos modelo de conduta. Tais instituições de ensino superior funcionavam como internato. Os professores, que também moravam nos colleges, tinham a responsabilidade de formar os jovens estudantes, dando-lhes o exemplo e assumindo o papel dos pais, situação denominada in loco parentis (Rudolph, 1990).

Vários colleges foram instituídos sem a autorização da Inglaterra; por essa razão seus fundadores sentiam-se bem mais ligados a seus patrocinadores locais do que à Coroa Britânica. Essa situação deu origem a um dos mais fortes componentes da estrutura de poder dos colleges : o Board of Trustees. Era uma espécie de Conselho Curador, grupo não residente, aberto a leigos, que governava a instituição, apontava as suas diretrizes e escolhia o presidente, que devia levar a efeito políticas emanadas pelos fundadores e por esse conselho. $\bigcirc$ corpo de professores era um sócio menor nessa estrutura de poder; ele não possuía o conhecimento, a organização nem a tradição dos mestres medievais e dependia, diretamente, daqueles que o sustentavam. Devido à pequena dimensão dos colleges, as disputas de poder costumavam ser pouco significativas. 
No período colonial, o caráter público ou privado dos colleges se confundia, uma vez que cada colônia possuía uma população bastante homogênea e a filiação religiosa perpassava quase todas as relações sociais. Com a independência dos Estados Unidos o caráter público, e portanto leigo, da educação passou a ser visto por alguns líderes da nova República como um objetivo a ser alcançado. A disputa entre o controle público ou privado, bem como a maior centralização ou diversificação no que concerne ao ensino superior norte-americano têm um divisor de águas no caso de Dartmouth College. Esse college foi fundado a partir de uma autorização emitida pela Coroa Inglesa. Na disputa de poder que seguiu à morte de seu primeiro presidente e à indicação de seu filho como sucessor, período em que os Estados Unidos já eram independentes, o Conselho Curador e os políticos locais do Estado de New Hampshire, onde se situa o college, tentaram definir, cada um à sua maneira, os futuros rumos da instituição.

Em I 816 o governo estadual tentou, pela legislação, criar a Universidade de Dartmouth, a partir do college do mesmo nome. Para isso necessitaria do consentimento do Conselho de Curadores. Esse consentimento foi alcançado através de um expediente: o aumento do número de curadores formando um conselho pró-criação da universidade. Como o conselho original recusava-se a obedecer a nova lei, a mesma instituição - Dartmouth College e Dartmouth University - tinha dois corpos administrativos. Essa situação levou o conselho original a processar o tesoureiro do college quando ele se negou a obedecer às suas ordens. A questão que se colocava era se Dartmouth era uma instituição pública ou não. Esse impasse colocou a disputa na esfera judicial.

A Corte Estadual, como era de se esperar, decidiu a favor do controle público da instituição. O caso foi à Suprema Corte de Justiça. E o julgamento nessa instância foi pró-conselho original, baseado no argumento de que a licença outorgada pela antiga metrópole era um contrato que devia ser honrado. Criar uma universidade pública estadual seria submeter-se a influências político-partidárias, o que não seria aconselhável e poderia, inclusive, levar à perda da confiança de benfeitores privados.

Essa decisão judicial equiparou, de certa forma, uma instituição educacional a uma corporação. A decisão incentivou a criação de inúmeros colleges de diferentes denominações religiosas, livres da ingerência governamental. Isto contribuiu para acentuar a diversidade, que é uma característica do sistema americano desde a sua origem. Contribuiu, também, para aumentar o sectarismo, acentuando as diferenças etno-religiosas da população. 
O ensino superior nos Estados Unidos, em suas origens, destinava-se a formação de pastores e outros líderes das comunidades, sendo definido como uma educação para homens e, mais especificamente, para homens brancos. A partir do século XIX esse monopólio passa a ser quebrado de uma forma tipicamente americana: surgem colleges para mulheres e para negros (Brubacher, Rudy, 1976).

Os colleges, pelo seu plano arquitetônico centrado no green, um quadrilátero gramado circundado pelos principais prédios (a capela, a biblioteca, as salas de aula, os dormitórios, os laboratórios etc.), reproduziam os valores de uma sociedade predominantemente rural. Em geral retirados da cidade, os colleges constituíam instituições quase totais. Com sua identidade religiosa, sua diversidade regional e étnica, suas especificidades por sexo e raça, tinham por missão não apenas formar o espírito dos seus jovens alunos, como conquistar-Ihes o coração. Essa densa atmosfera espiritual produz uma marca profunda que costuma acompanhar, ao longo da vida, todos aqueles que passam pelo mesmo college e é denominada a alma mater. Daí, também, a importância para as tradicionais universidades americanas do apoio financeiro dos alumni, exalunos, o que se faz sentir até hoje em dia (Leslie, 1992).

\section{Vivendo no college: greek system e outras formas de sociabilidade}

Na segunda metade do século XIX, estudantes universitários fundaram diversas organizações como grupos literários, sociedades secretas, times de futebol, clubes sociais, bem como fraternities (fraternidades). Estas últimas se constituíam em grupos fechados de estudantes, que residiam juntos em casas localizadas dentro ou na periferia dos campi e que, até hoje, podem ser identificadas por letras gregas nas suas fachadas. As primeiras fraternidades eram só para estudantes do sexo masculino. Passado algum tempo são fundadas as sororities para estudantes do sexo feminino. As várias fraternities e sororities, espalhadas por todo o país, formam o greek system, ou seja o sistema grego, que as une nacionalmente para que tenham maior organização. Esse sistema funciona como uma rede de apoio e de contatos sociais. Mediante ele os estudantes contam com apresentações e/ou recomendações, que podem facilitar a busca de estágios, empregos, empréstimos e outras facilidades; contam também com uma identidade que os diferencia. 
Para pertencer a uma fraternity não basta pagar uma mensalidade, é preciso se candidatar e ser escolhido. $O$ candidato preenche uma ficha com fotografia, dados pessoais, especificando as razões pelas quais elegeu tal fraternidade para pertencer. Quem escolhe os novos sócios são os antigos residentes. É interessante que um inscrito que tenha alguém da família que pertence ou pertenceu a uma fraternity, possui uma chance maior de ser escolhido, ele possui uma legacy, ou seja, um legado. Existem alguns rituais referentes à passagem da condição de pledged, (candidato), a membro da organização, ou seja, brother (irmão). $\bigcirc$ candidato a membro deve enfrentar desafios que the são impostos para mostrar que é merecedor de fazer parte da organização. A cada um dos novos membros selecionados é designado um irmão mais velho, que já mora na residência, para orientar o novato em termos de adaptação à vida no college e na fraternity. Existe todo um ritual de acolhimento aos novos sócios. Uma vez irmão, se é irmão por toda a vida. $O$ pertencer a uma fraternidade exige lealdade, pois a ligação com ela não se encerra com a obtenção do diploma do college. Ela, de fato, continua e se deve expressar de várias maneiras, desde o apoio a obras sociais, a ajuda para a construção de residências universitárias para novos membros até o apoio financeiro ao college.

São várias e complexas as razões pelas quais as fraternities e sororities se multiplicaram e se mantêm ativas até hoje. Logo que surgiram, algumas tinham como objetivo aprofundar os conhecimentos em literatura clássica, uma vez que muitos colleges antes da Guerra de Secessão ( | 86 | - | 865) ofereciam aos alunos uma experiência intelectual bastante limitada, devido ao sectarismo reinante em grande parte das instituições de ensino superior.

As fraternidades, com seu ambiente mais familiar, serviam e servem ainda de apoio, para a adaptação do calouro à nova vida no campus. $\bigcirc$ "deixar a família" para iniciar os estudos superiores significa para muitos estudantes não voltar mais para a casa dos pais. As fraternities passam a se constituir numa nova família, uma família de irmãos mais velhos e mais novos, ou seja, mais e menos experientes.

Numa perspectiva sociológica, pode-se afirmar que, quanto mais os colleges se democratizavam e passavam a aceitar grupos com menor capital cultural, as fraternities passaram a servir de filtro social. Elas tornam público que uns já trazem um verniz de berço, enquanto os demais dependem da sua passagem por circuitos escolares para adquirir capital cultural. $\bigcirc$ sistema grego possui toda uma estética que identifica seus membros. São camisetas, blusões, 
abrigos esportivos, chaveiros, pastas etc. Os Estados Unidos são considerados uma sociedade que apresenta valores de "igualdade manifesta e desigualdades sutis". Em matéria de residência no campus, pertencer a uma fraternidade é um sinal diacrítico, ou seja, marca de distinção (Bourdieu, 1979).

As fraternidades dão suporte a organizações de alumni, ex-alunos, que mantém um forte vínculo com a sua alma mater. Essa expressão, que a tradição inglesa passou para a norte-americana, refere-se não apenas àquele ambiente expresso em ideais, valores, normas, atitudes, mas também aos aspectos naturais e arquitetônicos, que caracterizam e dão vida a uma instituiç̧ão de ensino, ou seja, a sua filosofia, história e geografia. Muitos colleges são conhecidos por incentivar mais as atividades artísticas ou desenvolver nos seus estudantes o gosto pelo esporte, já outros, por exemplo, valorizam as atividades comunitárias etc.

As relações dos colleges e universidades com as fraternidades variam muito. As fraternidades realizam várias ações filantrópicas, como conceder bolsas de estudos. Os colleges são beneficiados com essas bolsas e com o significativo apoio financeiro de alumni, que pertencem a fraternities presentes no seu campus. No entanto, as fraternidades podem constituir-se em poderes paralelos. Os alunos, às vezes, se sentem mais ligados a suas fraternities do que ao college, deixando de obedecer as regras estabelecidas por este último. Para dar um exemplo, em muitos estados norte-americanos a idade mínima para ingerir bebidas alcóolicas em espaços públicos é a de 2 I anos. Isso faz com que grande parte dos undergraduates (alunos de graduação), devido a sua idade, seja proibida de beber socialmente. Para evitarem multa, os estabelecimentos exigem a apresentação de carteira de identidade aos jovens que pedem bebidas. As fraternities se tornam, principalmente entre os rapazes, lugares em que se pode beber sem ser molestado e algumas vezes isso significa beber de forma anti-social. Entre alguns professores universitários com quem tive a oportunidade de comentar esse assunto, as fraternidades são vistas como anacrônicas e excludentes, algumas delas se caracterizando por serem antiintelectuais e lugares em que se bebe demais. Desses professores nenhum pertencera a uma fraternity ou sorority.

Aproveitei um período de três meses que passei em Dartmouth College, em 2003, para pesquisar mais sobre fraternidades. Nas entrevistas que realizei com brothers e sisters senti-os muito ligados e orgulhosos de pertencer a suas respectivas fraternities ou sororities. Eu já tinha ouvido referência ao fato 
de que o sistema grego, como quase tudo nos Estados Unidos, é altamente segmentado em termos sociais. Um dos irmãos com quem estava fazendo uma entrevista se referiu às white letters. São as fraternidades predominantemente de brancos, alguns deles da elite wasp (white, anglo-saxon and protestant: brancos, anglo-saxões e protestantes).

Com a abertura do ensino superior para minorias, que até então dificilmente entravam na universidade, existe hoje fraternidades onde predominam americanos hifenados: os native-americans (indígenas americanos); os afroamericans (negros nascidos nos Estados Unidos); os asian-americans (americanos de ascendência asiática), os hispanics (latino-americanos, sejam brancos ou negros). Os que se consideram brancos são americanos não-hifenados, por hipótese euro-americans, muitos deles fazendo parte da elite dirigente.

Falando com uma sister, perguntei-lhe por que escolhera a sorority da qual fazia parte. Ela me disse que vinha de outro estado, seus pais não tinham freqüentado a universidade e não conhecia bem as diferenças logo que chegou em Dartmouth. Teve, pois, que se informar antes de escolher. Pedi que me comentasse as características das sororities para as quais ela não tinha se candidatado. Falou-me que algumas são muito festivas, outras, ao contrário, só pensam em estudar e brilhar academicamente, outras reúnem atletas, que estão sempre participando de competições esportivas, outra, é formada por moças casadouras, que pretendem achar um marido no college e se interessam por culinária. Ela escolheu a sua por ser mais nova, com um perfil menos estabelecido, que reúne jovens como ela. Frisou que o pertencer a uma sorority lhe ajudou bastante a se adaptar à nova vida.

Nas visitas que fiz a uma fraternitye a uma sorority, chamou-me a atenção a presença de bandeiras, diversos quadros nas paredes, que pareciam os de formatura em nossas faculdades, com as fotos de todos aqueles que foram aceitos em cada ano nas fraternidades. Os quartos eram compactos com cama, às vezes beliche, armário e mesa. Havia pequenas bibliotecas e sala de estudos, também pequenas. Isso se entende uma vez que a biblioteca do college, que se localiza a uma quadra, dispõe de todos os recursos bibliográficos necessários, vários computadores para uso da comunidade acadêmica, espaço amplo e confortável. Havia uma sala grande para jogos com mesa de pinguepongue e TV. O espaço social era bastante amplo, com sofás confortáveis, mesas para refeição, que poderiam ser arredadas para dar mais espaço por ocasião de festas. As duas residências que visitei tinham realizado festas recente- 
mente e estavam com os móveis do salão amontoados. Na fraternity havia caixas com garrafas e latas de bebidas alcóolicas vazias. As fraternidades são espaços privilegiados de sociabilidade. Entre elas há alianças e rivalidades, e inúmeras atividades sociais aí se realizam.

Mas, afinal o que diferencia as casas com letras gregas das demais residências estudantis?

Muitos colleges e universidades são cidades universitárias incluindo as residências onde moram os alunos, principalmente, de graduação. Esses dormitórios pertencentes aos colleges são prédios próximos ao núcleo central onde se encontram os prédios de salas de aulas, biblioteca, reitoria, bares, restaurantes etc.

A alocação dos estudantes é feita por um administrador, respeitando, na medida do possível, as características e preferências de cada um, expressas na ficha de inscrição. Práticos, os americanos perguntam ao futuro residente se fuma ou não, prefere dormir cedo ou tarde... para que seja colocado junto aos que têm gostos e hábitos semelhantes aos seus. $\bigcirc$ aluno pode mudar de quarto ou residência, desde que consiga vaga.

Além dos dormitórios, que estão abertos a todos (alunos e alunas), existem residências especiais reservadas para grupos específicos. No caso de Dartmouth, havia, por exemplo, a Latin American House. Perguntei ao funcionário encarregado dos latinos, desde a seleção, adaptação, até o acompanhamento nos cursos, se aquela era uma residência independente, em que os alunos estabeleciam as suas próprias regras. Ele me disse que não, essa é uma residência do college e, embora haja muita liberdade entre os residentes, os critérios de admissão são decididos pelo college. Perguntei-lhe se precisava ser latino-americano, para residir na casa. A resposta foi, também, negativa: estão aptos a se candidatar para a casa quaisquer estudantes que tenham, mediante seu currículo, mostrado interesse no estudo da América Latina. Isso inclui qualquer estudante do college. Há, também, exigências para os que foram selecionados. Pela orientação do próprio administrador da casa, uma vez por semana os estudantes devem-se reunir para uma refeição em comum, financiada pelo college, a fim de que tenham um contato mais íntimo como grupo de residência. Uma vez por mês a casa tem a responsabilidade de organizar um evento artístico ou cultural (apresentação de um filme, exposição de fotos, palestras etc.), que trate da América Latina e seja aberto à comunidade. 


\section{Sobre continuidade e mudanças: o desenvolvimento da educação superior}

Dos primeiros colleges do período colonial até a "multiversidade" de nossos dias, a educação superior norte-americana se expandiu muitíssimo, tornando-se um dos maiores e mais complexos sistemas do mundo. Para fazer uma breve síntese do desenvolvimento desse sistema, farei referência a algumas de suas características, dando maior ênfase a momentos que o levaram a responder certos desafios, postos pela sociedade e pelo governo federal, que se constituíram em mudanças.

Os land-grant colleges e as atividades de extensão

Até o final da primeira metade do século XIX, o ensino superior oferecido nos Estados Unidos era quase exclusivamente de orientação clássica. Apesar de já ter havido um processo de secularização, em que a formação em certas carreiras, como Medicina e Direito, passavam a ser oferecidas junto com a formação geral, havia muitas críticas às limitações do currículo, que apontavam a necessidade de uma educação mais técnica, voltada ao desenvolvimento do país. Grupos de agricultores reivindicavam uma educação democrática e aplicada à realidade por eles vivida. Como os estados não possuíam recursos suficientes para oferecer esse tipo de educação, o senador Justin Morril apresentou ao congresso um projeto de lei, a fim de garantir recursos federais a colleges que oferecessem cursos na área de agricultura. Aprovada, a lei deu origem aos land-grant colleges. O governo federal se comprometia a doar terras para os estados usarem-nas como bem thes aprouvesse, a fim de tornar possível a fundação de uma universidade estadual, que se voltasse para o atendimento das necessidades mais práticas em sua região (Lucas, 1994).

Eram grandes as dificuldades iniciais para por em prática tal objetivo: baixo prestígio dos cursos, alunos com pouca base de estudos, professores mal preparados e sem dispor de material didático apropriado. $\bigcirc$ estabelecimento de estações experimentais de agronomia favoreceu o progresso do conhecimento que passou a ser ministrado nos colleges. Da parte dos agricultores, proprietários de médio porte, havia, também, críticas ao caráter teórico do ensino e o desejo de possuir um conhecimento que atendesse suas necessidades cotidianas. Essa demanda levou alguns colleges a oferecer cursos rápidos para farmers, o que deu origem às atividades de extensão, uma contribuição tipicamente norte-americana à concepção de universidade. 
A marca de origem...

O desenvolvimento científico e as universidades de pesquisa

Por volta do final do século XIX, um modelo diferente de educação superior foi importado para os Estados Unidos, aquele da universidade de pesquisa alemã, baseada nas idéias de Humboldt. As atividades de pesquisa passaram a fazer parte das universidades, que assumiram um caráter de comprehensive, incluindo os colleges (cursos que envolvem os dois primeiros anos da graduação), as escolas profissionais e as atividades de extensão, bem como as atividades de pesquisa e os programas de pós-graduação. Algumas, inclusive, mantêm, até hoje, os divinity colleges (seminários de teologia).

As mudanças promovidas pelo desenvolvimento das atividades de pesquisa nas universidades só foram possíveis a partir de um longo e conflituoso processo de secularização que ocorreu no sistema de educação superior norte-americano. É interessante chamar a atenção para o fato de que isso foi facilitado à medida que houve a consolidação do college como um período de formação geral de quatro anos, necessário e essencial para o ingresso do estudante nos cursos profissionais de Medicina, Direito e nos programas de pós-graduação lato sensu, os mestrados e doutorados. Os colleges, tendo realizado sua missão de formar os undergraduates, colocavam o estudante em condições de passar para um curso científico ou profissional de caráter mais secular.

Na passagem do século XIX para o XX, o apoio de filantropos foi muito importante na criação e desenvolvimento de certos laboratórios ligados a universidades. Muitos doadores impunham condicionantes, como a proibição de ter uma sorority dentro do campus universitário. Eram comuns, também, doações para a construção de estádios de futebol.

As duas guerras mundiais, mudaram esse cenário, constituindo fatores decisivos na valorização da pesquisa de base, que passou a contar com o apoio sistemático do governo federal. No início as verbas destinavam-se às ciências físicas; mais tarde, também as ciências biológicas e as sociais passaram a ser contempladas e, finalmente, o incentivo se estendeu às humanidades (Geiger, 1986). Com a universidade de pesquisa, os departamentos tomam vulto e se tornam importantes para o desenvolvimento e consolidação de disciplinas acadêmicas. Diferentemente do catedrático na Alemanha, que detinha o poder, nos Estados Unidos são os chefes de departamento que dispõem de verbas para planejar as atividades futuras, podendo em alguns casos interferir na seleção e contratação de novos professores. Para que a pesquisa pudesse se desenvol- 
ver e consolidar, programas de pós-graduação foram criados para a formação de pesquisadores.

Nem todas as universidades norte-americanas se transformaram em universidades de pesquisa. Existem muitas universidades públicas estaduais voltadas principalmente à formação de professores e outros profissionais. Vários colleges mais antigos permaneceram fiéis à sua missão, sem diversificar muito as suas funções. Outras pequenas universidades privadas também não deram o salto de qualidade para se tornarem instituições de pós-graduação e pesquisa.

\section{A democratização do ensino e os community colleges}

No início do século $X X$ surgiram os junior colleges, localizados em pequenas cidades. Eles ofereciam os dois primeiros anos do college e tinham a função de transferência, ou seja, aqueles alunos que desejassem concluir seus estudos num college de universidade e apresentassem bom desempenho, poderiam fazê-lo. Mais tarde, houve uma pressão para que os junior colleges oferecessem disciplinas técnicas. Surgem, assim, os community colleges, que atendem a um grande contingente de alunos (na Califórnia e em Nova York há o ingresso irrestrito para todos aqueles que se mostrarem capazes de aproveitar um curso superior, mesmo que não sejam portadores de um diploma de nível médio). Esses colleges, não apenas cumprem a função de transferência para certos alunos de orientação mais acadêmica, como, também, desenvolvem cursos completos, alguns de quatro anos, de orientação mais prática, voltados para atender a necessidades do mercado de trabalho local. A maior parte dos community colleges pertence ao setor público estadual (Diener, 1986).

Além dos community colleges, contribuiu para a expansão e democratização do ensino superior americano o programa de bolsas concedidas pelo governo federal, para aqueles que tinham lutado na Segrunda Guerra Mundial. Essas bolsas favoreceram a diversidade do sistema, uma vez que os bolsistas eram livres para escolher o tipo de educação que mais bem thes conviesse. Atendida essa demanda reprimida, pensava-se que o sistema deixaria de se expandir. No entanto, o contingente de mulheres, de minorias e de pessoas de terceira idade, que ingressava pela primeira vez nos colleges ou desejava continuar seus estudos, manteve constante a expansão das matrículas do ensino superior. 
A marca de origem...

\section{A EDUCAÇÃO SUPERIOR NO BRASIL}

\section{Instituição fundante: as faculdades brasileiras}

Brasil colônia não dispôs de ensino superior em seu território até o início do século XIX. Os estudantes da elite colonial portuguesa, considerados portugueses nascidos no Brasil, tinham de se deslocar até a metrópole para lá se graduarem. Na colônia, o ensino formal esteve a cargo da Companhia de Jesus. Os jesuítas dedicavam-se à cristianização dos indígenas organizados em aldeamentos, à formação do clero em seminários teológicos e à educação dos filhos da classe dominante nos colégios reais. Nestes últimos, era oferecida uma educação medieval-latina com elementos de grego, que preparava seus estudantes para freqüentar a Universidade de Coimbra, em Portugal. Essa universidade tinha como uma de suas missões a unificação cultural do império português. Dentro do espírito da Contra-Reforma, ela acolhia os filhos da elite portuguesa que nasciam nas colônias, visando a desenvolver neles uma homogeneidade cultural avessa a questionamentos quanto à fé católica e à superioridade da metrópole em relação à colônia. A Universidade de Coimbra, no dizer de Anísio Teixeira, foi a nossa "primeira universidade". Nela se graduaram em Teologia, Direito Canônico, Direito Civil, Medicina e Filosofia, durante os primeiros três séculos de nossa história, mais de 2.500 jovens nascidos no Brasil (Teixeira, 1989).

Em I808, a Família Real Portuguesa deixou Lisboa rumo ao Brasil, para escapar das tropas napoleônicas que invadiram Portugal. Quando Dom João VI, então príncipe regente, chegou à Bahia, os comerciantes locais solicitaram-lhe a criação de uma universidade, dispondo-se a colaborar com uma significativa contribuição financeira para o seu custeio. Em vez de universidade, foi criado, em Salvador, o Curso de Cirurgia, Anatomia e Obstetrícia. Com a transferência da corte para o Rio de Janeiro, foram criadas nessa cidade, uma Escola de Cirurgia, Academias Militares, Escola de Belas-Artes. Foram, também, criados o Museu Nacional, a Biblioteca Nacional e o Jardim Botânico.

É importante frisar que as primeiras faculdades brasileiras - Medicina, Direito, Politécnica - estabelecidas no século XIX, eram profissionalmente orientadas, independentes umas das outras, instituições seculares, cuja organização didática e estrutura de poder baseavam-se em cátedras vitalícias. A independência do país, em 1822, não modificou o quadro da educação supe- 
rior. Durante o império foram criadas duas Faculdades de Direito, uma em Olinda, e outra, em São Paulo. Em Ouro Preto, região de extração de ouro, foi criada uma Escola de Minas.

\section{Sobre continuidade e mudanças: o desenvolvimento da educação superior}

A criação de universidades

Tanto as faculdades quanto a universidade no Brasil surgem tardiamente. Nossa primeira universidade, que existe até hoje, a Universidade do Rio de Janeiro, foi criada por decreto, em 1920, tendo nascido da vinculação administrativa de faculdades preexistentes. Ela não oferecia novas alternativas ao ensino superior, quer nos seus objetivos, quer na forma de funcionamento: conservou a orientação meramente profissional dos cursos, a compartimentalização de faculdades, a estrutura de poder apoiada na cátedra, o caráter elitista do ensino; manteve-se alheia às necessidades da maior parte da população brasileira, não incentivou o desenvolvimento da ciência e da tecnologia (Fávero, 1980).

Francisco Campos, primeiro ministro da educação do país, decretou em 1931 o Estatuto das Universidades Brasileiras, vigente até 1961. De acordo com o Estatuto, para a criação de uma universidade, seriam necessárias, pelo mínimo, três faculdades dentre as seguintes: Direito, Medicina, Engenharia, Educação, Ciências e Letras. Essas faculdades seriam ligadas por vínculos administrativos, embora pudessem manter a sua autonomia jurídica.

A criação da Universidade de São Paulo - USP - representa uma ruptura nesse modelo tradicional. Fundada em 1934, pode ser considerada a primeira tentativa bem-sucedida de criar uma universidade no Brasil capaz de inovar em seus objetivos. Em termos científicos, a USP notabilizou-se como centro de pesquisa em diversas áreas do saber. Na esfera organizacional, no entanto, a idéia de fazer da recém-criada Faculdade de Filosofia, Ciências e Letras, um eixo central e integrador das atividades de ensino básico e de pesquisa, fracassou devido, em grande parte, à resistência das faculdades tradicionais. Elas não queriam abrir mão do processo de seleção e formação dos seus alunos desde que esses entrassem na universidade.

$\bigcirc$ Rio de Janeiro, então capital da República, constituiu palco privilegiado onde se organizaram e se defrontaram diversos grupos, que lutaram para estabelecer a hegemonia quanto à definição do papel da universidade brasilei- 
ra. Lá são criadas três universidades - a Universidade do Distrito Federal, a Universidade do Brasil e a Pontifícia Universidade Católica - que, de certa forma, expressam as clivagens ideológicas entre os educadores da época.

Em 1935, Anísio Texeira, então Diretor de Instrução do Distrito Federal, criou por meio de um decreto municipal, a Universidade do Distrito Federal, voltada principalmente à renovação e ampliação da cultura. Tal acontecimento constituiu uma vitória dos educadores liberais. Pelo seu posicionamento político a favor da escola pública e gratuita, a iniciativa de Anísio Teixeira não contou com o apoio do governo federal, nem com o dos setores ligados à lgreja Católica.

Devido ao clima político e à ingerência direta do governo central, a Universidade do Distrito Federal teve apenas quatro anos de existência. Extinta por decreto presidencial em 1939, seus cursos foram transferidos para a Universidade do Brasil, nome que passou a ter a antiga Universidade do Rio de Janeiro. Idealizada por Capanema, então ministro da educação do governo de Getúlio Vargas durante o Estado Novo, a Universidade do Brasil deveria servir de modelo para qualquer instituição de ensino superior existente em todo o território nacional; ela fixaria o padrão de ensino superior do país (Schwartzman, 1994).

Em contrapartida, a intelectualidade católica brasileira dessa época temia as idéias liberais e a influência norte-americana nos meios educacionais, pois via nisso um risco de enfraquecimento do catolicismo. Sob a administração e orientação pedagógica dos jesuítas, reunindo as já existentes Faculdades de Direito, Filosofia e Serviço Social, foi criada em 1946 a primeira universidade católica do país, que recebeu da Santa Sé o título de Pontifícia. Essa passou a ser exemplo para a criação de outras universidades católicas no território nacional.

De 1945 a 1964 o ensino superior brasileiro viveu uma fase de integração, com a criação de universidades mediante vinculação administrativa de faculdades já existentes e com a federalização de grande parte de estabelecimentos de ensino de terceiro grau. No final do período populista, 65\% dos estudantes do ensino superior estavam matriculados em universidades. Esse período legou um modelo de universidade, organizado com base em faculdades tradicionais, que ofereciam cursos profissionalizantes para a formação da elite dirigente (Cunha, 1983).

Em 1961 foi promulgada a primeira Lei de Diretrizes e Bases da Educação Nacional que, apesar de permitir flexibilidade, consolidou, na prática, o 
modelo tradicional: manteve a cátedra vitalícia, as faculdades isoladas e as universidades compostas pela simples justaposição dessas últimas sem maior preocupação com a pesquisa.

No mesmo ano, foi criada a Universidade de Brasília - UnB -, a primeira universidade do país nascida de um plano definido, sem incluir faculdades profissionais preexistentes. Ela fazia parte do projeto nacional-desenvolvimentista. Com uma estrutura mais integrada, flexível e moderna, contrapunha-se ao modelo de universidade segmentada em faculdades compartimentadas. Nela, o departamento substituía a cátedra como unidade de ensino e pesquisa. As inovações introduzidas com a UnB serviram, em parte, de modelo para a reforma universitária do final da década de 60.

\section{A reforma universitária de 1968 e a pós-graduação}

Após o golpe de 1964, os militares, ao tomarem o poder, passaram a ter uma ingerência direta dentro das universidades: foi afastado um grande número de professores, principalmente na Universidade de Brasília; foram ainda criadas assessorias de informação nas instituições federais de ensino superior, para controlar as atividades de caráter "subversivo", tanto de professores quanto de alunos. Em 1968, ano de manifestações estudantis em vários países, também os estudantes brasileiros se mobilizaram. "Excedentes", alunos que haviam passado no exame vestibular sem obter uma vaga na universidade, organizaram-se para reivindicar mais vagas. Em algumas universidades foram criados cursos paralelos pelos próprios excedentes.

A reforma universitária, que permanecera por um tempo em estado latente, sendo discutida apenas nos gabinetes da burocracia estatal, assumiu conotação política. $\bigcirc$ Congresso Nacional aprovou em questão de semanas a Lei n. 5.440/68, Lei da Reforma Universitária. Mediante a reforma, foram criados os departamentos, em substituição às cátedras, nos quais a chefia tem caráter rotativo. $\bigcirc$ exame vestibular deixou de ser eliminatório, passando a ser classificatório; abriu-se a possibilidade de cada estudante escolher mais de um curso na sua inscrição para o vestibular, o que possibilitou um redirecionamento de candidatos dos cursos mais procurados para os que tinham menor demanda. Foram criados cursos de curta duração, principalmente nas áreas técnicas e de formação de professores. Foi incentivado o sistema de créditos. Ficou, também, estabelecido um ciclo básico, que deveria ser oferecido para os alu- 
nos que ingressavam na universidade. Esses foram fatores que visavam a um maior aproveitamento das vagas pela racionalização dos recursos existentes, possibilitando aumentar o contingente estudantil nas universidades públicas, sem elevar muito os custos operacionais.

Ao preconizar, paralelamente, a indissociabilidade das atividades de ensino, pesquisa e extensão, o regime de tempo integral e dedicação exclusiva para os professores, valorizando a sua titulação e a produção científica, a reforma foi um divisor de águas que possibilitou a profissionalização dos docentes e criou condições propícias ao desenvolvimento do sistema de pós-graduação e das atividades científicas no país. A Lei n. 5.540 dirigia-se, principalmente, às instituições federais de ensino superior. Pelo texto legal, a universidade era o modelo institucional a ser seguido; os estabelecimentos isolados deveriam constituir exceção, para atender situações específicas. Cabia à universidade o desenvolvimento das atividades de ensino, pesquisa e extensão. Essas três funções básicas da universidade foram consideradas indissociáveis.

○ sistema federal permaneceu fiel a essa orientação da reforma, tendo ampliado de forma controlada as matrículas dos cursos de graduação, pela racionalização de recursos prevista pela nova disposição legal, sem criar faculdades isoladas. Paralelamente, aproveitando as oportunidades de recursos materiais que o governo colocava à disposição para a pesquisa e formação de pesquisadores, as grandes universidades públicas implantaram um sistema de pós-graduação, que tem servido para a qualificação dos docentes de nível superior e o desenvolvimento da pesquisa no país.

Vários fatores impulsionaram a implantação e o desenvolvimento da pósgraduação no Brasil. Em primeiro lugar, a valorização de recursos humanos de alto nível, principalmente nas áreas técnicas, visando à implantação do projeto de modernização conservadora, sustentado pelos governos militares. Esse objetivo foi atingido com uma vontade política traduzida na liberação de verbas diretamente direcionadas ao desenvolvimento de programas de pós-graduação stricto sensu. Para isso muito contribuíram as agências de fomento ao desenvolvimento científico. A Coordenação de Aperfeiçoamento do Pessoal de Nível Superior - Capes - qualificou no exterior e mais tarde nos programas nacionais consolidados, um grande número de docentes universitários. $\bigcirc$ Conselho Nacional de Desenvolvimento Científico e Tecnológico - CNPq financiou projetos de pesquisa e distribuiu bolsas para professores pesquisadores, bem como bolsas de mestrado e doutorado. 
As universidades públicas, tornam-se o locus principal das atividades de pesquisa, ainda incipientes no país. A carreira docente nas universidades públicas federais passou a estimular a titulação e produção científica dos professores universitários, sendo a sua profissionalização assegurada pela possibilidade de obter o regime de tempo integral e dedicação exclusiva, algo novo no país. Essas medidas tornaram compensadora a carreira do magistério universitário no setor público, atraindo jovens professores para as atividades acadêmicas.

Tal como foi planejada, a pós-graduação não se integrava na estrutura de poder baseada na cátedra, como era a realidade universitária antes de 1968. Após a reforma foi abolida a figura do catedrático, legal e simbolicamente, pois na prática, o que valia eram os títulos daqueles jovens professores que se qualificaram no exterior e passaram a liderar o processo de implementação dos programas de pós-graduação no país. Estes últimos, ao contrário dos cursos de graduação no Brasil, sempre tiveram ampla liberdade de se auto-regular: pelo grupo seleto de professores com a qualificação exigida, eles selecionavam seus alunos com critérios próprios, escolhiam seu coordenadores, tinham, também, independência quanto ao uso de seus recursos e até, em certos casos, quanto à escolha de novos professores. Organizavam, avaliavam e reformulavam sua proposta curricular de forma não burocrática, a partir da realidade e da dinâmica do programa, situação que se mantém até hoje. Essa flexibilidade, em termos de uma "desinstitucionalização", que caracterizou a situação inicial dos programas, foi positiva ao desenvolvimento da pós-graduação. Já os cursos de graduação, atrelados a currículos mínimos, tendiam a valorizar o seu significado profissional, garantido pela regulamentação das profissões e reforçado pela tradição corporativa muito forte no Brasil. Seus professores, alguns com atividades profissionais fora da universidade, enfrentando uma burocracia complexa e pesada, tinham mais dificuldade de mudar a proposta dos cursos aos quais estavam ligados.

Foram realizados planos nacionais para o desenvolvimento da pós-graduação. Em 1972, a Capes iniciou um programa de avaliação dos cursos de mestrado e doutorado que tem servido de orientação às suas políticas. Para tal, são organizadas comissões formadas por especialistas das diferentes áreas de saber, indicados pela comunidade científica. Essa avaliação tem levado em conta a qualificação de professores, produção científica dos programas, número de egressos, tempo médio para a titulação dos alunos, instalações materiais, biblioteca etc. Foi, também, de grande importância a criação de inúmeras as- 
sociações nacionais de pesquisa e pós-graduação em vários ramos do conhecimento e o incentivo dado a elas. Os encontros anuais dessas associações passaram a integrar a comunidade científica de áreas afins e de diferentes regiões e universidades.

Todas essas medidas criaram condições propícias ao desenvolvimento de programas de pós-graduação e de atividades de pesquisa, como partes altamente valorizadas do nosso sistema universitário. Pode-se afirmar que essas políticas para a pós-graduação foram bem-sucedidas, já que o Brasil conta com um sistema que é considerado referência entre os de países em desenvolvimento. Também são prova do sucesso os atuais intercâmbios com universidades de outros países que se realizam, atualmente, numa situação mais simétrica, de parceria.

\section{A segmentação do sistema de educação superior}

Após a reforma universitária, o número de estudantes da educação superior apresentou uma impressionante expansão. Esta expansão modificou o perfil do sistema de forma marcante, acentuando a sua segmentação interna. Houve um divórcio entre uma expansão quantitativa e outra qualitativa. $\bigcirc$ grande aumento das matrículas de graduação ocorreu no setor privado, em faculdades isoladas de baixo padrão acadêmico, dando lugar a um processo de paroquiamento do ensino superior (Oliven, 1990). Essa expansão quantitativa não modificou a orientação profissionalizante dos cursos oferecidos, marca da educação superior no Brasil, desde a sua origem, no início do século XIX.

Paralelamente, o setor público tomou a liderança do desenvolvimento da pós-graduação e também das atividades de pesquisa. Essa expansão qualitativa modernizou um segmento importante do sistema universitário brasileiro. A dualidade do sistema não se refletia apenas em termos dos setores público, onde se concentrava a maioria das universidades, e privado, onde se encontrava o maior número de estabelecimentos isolados. A segmentação interna atingiu o próprio setor público com a expansão e fortalecimento dos programas de pós-graduação e um certo descaso quanto aos cursos de graduação, que foram, em boa parte, relegados a um segundo plano. $\bigcirc$ computador passou a ser o grande auxiliar nos processos, cada vez mais despersonalizados de seleção de candidatos à universidade, baseados em provas com questões de múltipla escolha apenas. 
Os governos autoritários viam com bons olhos a expansão do setor privado no nível de graduação. A pulverização de faculdades isoladas, dificultava a mobilização política dos estudantes. Já as universidades públicas, consideradas centros de subversão, sofreram um processo de "limpeza ideológica" pelas cassações de professores, para se tornarem confiáveis aos olhos dos militares.

Com a democratização da sociedade brasileira, o caráter paroquial de inúmeras faculdades isoladas tornou-se anacrônico e economicamente insustentável; assim, na década de 80 , são criadas muitas universidades no setor privado a partir da aglutinação de faculdades isoladas. Na década seguinte, as universidades que mais cresceram, em termos de número de matrículas, são as grandes universidades do setor privado.

\section{TRAÇANDO UM PARALELO}

Como já vimos, a tradição do college, nos Estados Unidos, teve início com Harvard na primeira metade do século XVII. O college nasceu privado, mais ligado ao seu Board of Trustees do que à Coroa Inglesa, e com profunda orientação religiosa. Como um de seus objetivos mais importantes era a formação de pastores, valorizava muito a questão da formação do caráter. Os colleges, tendo passado por um processo de secularização ao longo de sua história, voltam-se, atualmente, para a formação geral do estudante e desenvolvimento da cidadania, oferecendo, também, na sua modalidade de community college, disciplinas práticas voltadas ao mercado de trabalho local.

A passagem do college para a universidade é um processo longo e complexo, com resultados variados. Nem todos seguem esse caminho: há os que permanecem como colleges até hoje, valorizando mais a sua missão educativa, isto é, dedicando-se mais ao ensino de alta qualidade do que à pesquisa; outros, criados como colleges, atendem a grande demanda por ensino superior, sem as possibilidades e a pretensão de se tornarem universidades. A origem do college é de natureza não profissional.

As primeiras faculdades no Brasil, que datam do século XIX, dependeram para a sua criação da vontade de um ator governamental central, no caso Dom João VI. Essas faculdades, de Medicina e mais tarde de Direito, localizadas nas principais cidades, eram altamente elitistas e, seguindo o modelo das grandes escolas francesas, eram instituições seculares, de formação de profissionais, mais voltadas ao ensino do que à pesquisa. A organização didática e a 
estrutura de poder baseavam-se em cátedras vitalícias. $\bigcirc$ catedrático era referido como o "lente proprietário", aquele que dominava o seu campo de saber. Ele escolhia seus assistentes e permanecia no topo da hierarquia acadêmica por toda a sua vida.

No Brasil, os professores catedráticos dos tradicionais cursos de Medicina e Direito costumavam ser profissionais de renome que se dedicavam parcialmente a suas atividades docentes. Eles eram exemplos profissionais a serem seguidos. Nos Estados Unidos, os professores constituíam exemplos morais, eles viviam nos colleges com os alunos e assumiam, simbolicamente, a responsabilidade na formação de caráter de seus estudantes, mediante sua função in loco parentis.

Os colleges e universidades norte-americanos tradicionais apresentam, em geral, um traçado arquitetônico que dá ênfase ao quadrilátero central ao redor do qual se erigiram os prédios principais. Voltados para si mesmos, eles representavam um microcosmo social com pouca relação com a cidade onde se localizavam. Dos séculos XVII ao XIX, colleges e universidades sentiam-se identificados, principalmente, com os valores rurais da sociedade americana.

No Brasil as faculdades foram, desde a origem, construídas nos centros das principais cidades. Os retirados campi de algumas das nossas universidades são uma realidade bem mais tardia e seguiram o modelo norte-americano. As "passeatas dos calouros", antes tão populares, eram feitas para a população das cidades. Palestras, espetáculos artísticos, exposições são não apenas abertos, mas freqüentados pela população citadina, que mora próximo dos prédios históricos das antigas faculdades. Os campi muito retirados dificilmente atraem pessoas fora da sua comunidade acadêmica.

Nos Estados Unidos, a educação superior pública é atribuição dos governos estaduais; eles não têm um conjunto de universidades federais como no Brasil. Mais de uma vez, lá, foi discutido o projeto de uma universidade pública nacional que servisse de padrão institucional a todo o território, mas a idéia nunca foi posta em prática. Em nosso país tivemos, por algum tempo, a Universidade do Brasil, que deveria servir de modelo a todas as demais. Tanto lá como aqui, colleges e faculdades existiram antes da criação de universidades. Lá as grandes universidades integraram o college, junto com as escolas profissionais, as atividades de extensão, os programas de pós-graduação e atividades de pesquisa, formando uma multiversidade. Os estudantes ingressam na universidade através do college, eles na realidade são undergraduates ; só 
depois da formatura, que lá se chama commencement, é que se dirigem a um curso profissionalizante (Medicina, Direito ou mestrado e doutorado em Química, História ou Literatura, por exemplo) onde passam a ser graduate students.

A experiência acadêmica do college, atualmente, caracteriza-se por ser ampla e flexível. No caso dos colleges de universidade e aqueles com orientação acadêmica, ao final dos quatro anos o aluno deve ter concluído um major e, às vezes, um minor, ou seja, um elenco de matérias relacionadas com uma disciplina como Antropologia, Biologia ou uma temática, como América Latina, Políticas Públicas etc. Major e minor podem ou não estar relacionados entre si. Como não existe um exame de ingresso padrão de um curso para outro e de uma universidade para outra, majors e minors não necessitam estar diretamente relacionados com o curso profissional que o candidato deseja seguir. A maioria dos estudantes, durante o college, procura escolher disciplinas que sirvam de base para seus estudos posteriores em cursos profissionais. Em algumas situações, no entanto, parece existir uma certa valorização, em cursos altamente seletivos, de bons candidatos que fogem ao padrão convencional. É o caso de médica norte-americana que conheço, formada em Harvard, cujo major era em línguas mortas, incluindo aramaico, e de uma candidata ao curso de medicina, que estudou artes no college e disse-me que essa seria a única chance de ter uma formação mais ampla se ingressasse na medicina. $\bigcirc$ college, portanto, é de orientação não-profissional.

A faculdade no Brasil, desde sua origem até hoje, é de natureza profissional. Nesse caso, o jovem é obrigado a escolher um curso profissionalizante antes mesmo de ingressar na universidade, quando se prepara para o vestibular, já que a profissão aqui é definida pelo diploma de graduação. Quando se forma, ele cola grau, ou seja, faz um juramento que o liga ao desempenho de sua profissão. Por muito tempo, os cursos de graduação tinham um currículo mínimo traçado pelo Conselho Federal de Educação para todo o território nacional. Esses currículos tornavam-se máximos pela grande carga horária obrigatória, ou também, pelo reduzido número de escolhas que alguns estabelecimentos isolados ofereciam a seus estudantes.

Com a Lei de Diretrizes e Bases da Educação de 1996, os currículos mínimos vêm sendo substituídos por parâmetros curriculares, que procuram ser orientações mais flexíveis. Isso contribui para tirar o gesso que, por muito tempo, aprisionou o currículo dos cursos de graduação dificultando experimentações inovadoras. 
Um dos fatores que reforçam a orientação profissional dos cursos de graduação no Brasil é a existência de uma política governamental que assegura direitos e privilégios aos egressos dos cursos de graduação pela garantia da regulamentação das profissões. Ocupações que nos Estados Unidos não são regulamentadas por lei, no Brasil o são. Aquelas que ainda não têm o seu exercício regulamentado lutam pelo reconhecimento legal.

Os colleges jamais se profissionalizaram como as faculdades brasileiras. Ao contrário, a partir do século $X X$ eles passaram a ser pré-requisito para aqueles que quisessem fazer estudos profissionais, exigência que antes nem sempre ocorria. Eles também se democratizaram adaptando-se a uma demanda social cada vez mais heterogênea de grupos com baixa renda, minorias, pessoas de terceira idade etc. Essa função de democratização da educação superior foi assumida pelos governos estaduais, que têm o maior número de matrículas nos novos colleges e universidades, cada vez mais citadinos. A educação superior no Brasil também se expandiu, mas foi o setor privado que assumiu a liderança na oferta de vagas nos cursos de graduação, primeiro nas faculdades isoladas interioranas e na periferia das grandes cidades, e agora principalmente por intermédio das maiores universidades, que possuem milhares de alunos e se situam nas regiões metropolitanas.

O objetivo desse trabalho foi o de chamar a atenção para o significado simbólico das instituições fundantes no desenvolvimento dos sistemas de educação superior em dois países. A sociedade norte-americana da primeira metade do século XVII é bem diferente da do início do século XXI, mas a idéia de college como uma instituição de formação do caráter, formação geral, desenvolvimento pessoal e da cidadania permanece nos mais variados tipos de colleges, desde os mais antigos e tradicionais, os land-grant colleges, os colleges das universidades, os junior colleges, os community colleges, os colleges das regiões metropolitanas.

No Brasil as primeiras faculdades formavam uma elite profissional, os bacharéis (Adorno, 1988) que ajudaram na ordenação jurídica da nova nação, mais tarde médicos e engenheiros que se encarregaram de traçar e executar as políticas sanitárias e construir as obras de engenharia urgentes para a nação que se tornara república (Nadai, 1987). Eles também eram os grandes educadores da época. Entre as primeiras faculdades de direito que datam do século XIX e uma faculdade de Direito localizada no interior brasileiro, hoje em dia, há enorme diferença, mas as duas têm algo em comum: seus alunos colam grau e são 
credenciados para exercer uma profissão, mesmo que atualmente essa credencial tenha de ser validada pelos exames da Ordem dos Advogados do Brasil.

Essas diferenças explicam porque a USP, ao ser criada em 1934, conseguiu levar a efeito o seu ideal de pesquisa, salientando-se como instituição produtora de conhecimento, enquanto a tentativa de fazer da Faculdade de Filosofia o centro integrador da nova universidade, que selecionaria seus candidatos e ofereceria uma formação geral para que esses depois entrassem nas escolas profissionais, não teve êxito. As faculdades tradicionais resistiram à tentativa da recém-criada Faculdade de Filosofia de exercer a liderança na seleção e formação geral dos estudantes universitários. Ela estaria assumindo a função de college e diminuindo o poder das faculdades profissionais. Também a elite paulista relutou em mandar seus filhos para uma instituição tão nova e ainda sem tradição no país.

Um outro exemplo significativo é o da Reforma de 1968. Sua influência se faz sentir ainda hoje em muitos aspectos como o sistema de créditos, os departamentos, o desenvolvimento da pós-graduação, o vestibular classificatório etc. Mas pouco restou das experiências de ciclo básico, uma tentativa malsucedida de implementar algo semelhante ao college norte-americano em terras brasileiras. Atualmente, quando se discute uma nova reforma universitária, falase na possibilidade de dividir o curso de graduação em dois ciclos, sendo o primeiro ciclo de caráter acadêmico mais geral, com a duração de dois anos. É preciso não esquecer que o Brasil nunca abriu mão do caráter profissionalizante dos cursos de graduação oferecidos em faculdades e universidades, que dão aos egressos a sua identidade profissional.

Estados Unidos e Brasil possuem modelos bem diferentes de educação superior. Tanto um quanto outro, no entanto, mantém de forma bastante significativa sua marca de origem. Esse trabalho procurou mostrar como essa marca se faz presente ao longo do desenvolvimento e expansão dos dois sistemas.

\section{REFERÊNCIAS BIBLIOGRÁFICAS}

ADORNO, S. Os Aprendizes do poder : o bacharelismo liberal na política brasileira. Rio de Janeiro: Paz e Terra, 1988.

BOURDIEU, P. La Distinction. Paris: Editions de Minuit, 1979. 
A marca de origem...

BRUBACHER, J.; RUDY, W. Higher education in transition. 3. ed. revised and enlarged. New York: Harper \& Row Publishers, 1976.

CUNHA, L. A. A Universidade crítica. Rio de Janeiro: Francisco Alves, 1983.

DIENER, T. Growth of an american invention: a documentary of junior and community colleges. Westpoint: Greenwood Press, 1986.

FÁVERO, M. de L. Universidade \& poder. Rio de Janeiro: Achimé, 1980.

GEIGER, R. L. To Advance knowledge: the growth of American research universities 1900 1940. Oxford: Oxford University Press, 1986.

GRAHAM, R. B. The Dartmouth story: a narrative history of the colleges buildings, people and legends. Hanover: Dartmouth Bookstore Inc., 1990.

LESLIE, W. B. Gentlemen and scholars : college and community in the "age of the university," |865-1917. University Park: Pennsylvania State University Press, 1992.

LUCAS, C. J. American higher education : a history. New York: St. Martin's Griffin, 1994.

MARSDEN, G. M. The Soul of the american university: from protestant establishment to established non belief. Oxford: Oxford University Press, 1994.

NADAl, E. Ideologia do progresso e o ensino superior. São Paulo: Loyola, 1987.

OLIVEN, A. C. A Paroquialização do ensino superior : classe média e sistema educacional no Brasil. Petrópolis: Vozes, 1990.

RUDOLPH, F. The American college and university : a history. Athens: University of Georgia Press, 1990.

SCHWARTZMAN, S. Tempos de Capanema. Rio de Janeiro: Paz e Terra, 1994.

TEIXEIRA, A. O Ensino superior no Brasil : análise e interpretação de sua evolução até 1960. Rio de Janeiro: Fundação Getúlio Vargas, 1989.

Recebido em: agosto 2004

Aprovado para publicação em: novembro 2004 